\title{
Respiratory Abnormalities Resulting from Midcervical Spinal Cord Injury and their Reversal by Serotonin 1A Agonists in Conscious Rats
}

\author{
Howard Choi, ${ }^{1,2,3}$ Wei-Lee Liao, ${ }^{1,2,3}$ Kimberly M. Newton, ${ }^{1,3}$ Renna C. Onario, ${ }^{1,3}$ Allyson M. King, ${ }^{1,3}$ Federico C. Desilets, ${ }^{1,3}$ \\ Eric J. Woodard, ${ }^{1}$ Marc E. Eichler, ${ }^{1}$ Walter R. Frontera, ${ }^{2}$ Sunil Sabharwal, ${ }^{2,3}$ and Yang D. Teng ${ }^{1,2,3}$ \\ ${ }^{1}$ Department of Neurosurgery, Harvard Medical School, Brigham and Women's Hospital and Children's Hospital Boston, Boston, Massachusetts 02115, \\ ${ }^{2}$ Department of Physical Medicine and Rehabilitation, Harvard Medical School, Spaulding Rehabilitation Hospital, Boston, Massachusetts 02114, and \\ ${ }^{3}$ Spinal Cord Injury Research and Service, Veterans Affairs Boston Healthcare System, West Roxbury, Massachusetts 02132
}

Respiratory dysfunction after cervical spinal cord injury (SCI) has not been examined experimentally using conscious animals, although clinical SCI most frequently occurs in midcervical segments. Here, we report a C5 hemicontusion SCI model in rats with abnormalities that emulate human post-SCI pathophysiology, including spontaneous recovery processes. Post-C5 SCI rats demonstrated deficits in minute ventilation $(\mathrm{Ve})$ responses to a $7 \% \mathrm{CO}_{2}$ challenge that correlated significantly with lesion severities (no injury or $12.5,25$, or 50 $\mathrm{mm} \times 10 \mathrm{~g}$ weight drop; New York University impactor; $p<0.001)$ and ipsilateral motor neuron loss $(p=0.016)$. Importantly, C5 SCI resulted in at least 4 weeks of respiratory abnormalities that ultimately recovered afterward. Because serotonin is involved in respirationrelated neuroplasticity, we investigated the impact of activating $5-\mathrm{HT}_{1 \mathrm{~A}}$ receptors on post-C5 SCI respiratory dysfunction. Treatment with the 5-HT ${ }_{1 \mathrm{~A}}$ agonist 8-hydroxy-2-(di- $n$-propylmino)tetralin (8-OH DPAT) $(250 \mu \mathrm{g} / \mathrm{kg}$, i.p.) restored hypercapnic Ve at 2 and 4 weeks after injury (i.e., $\sim 39.2 \%$ increase vs post-SCI baseline; $p \leq 0.033$ ). Improvements in hypercapnic Ve response after single administration of 8-OH DPAT were dose dependent and lasted for $\sim 4 \mathrm{~h}$ ( $p \leq 0.038$ and $p \leq 0.024$, respectively). Treatment with another 5-HT ${ }_{1 \mathrm{~A}}$ receptor agonist, buspirone $\left(1.5 \mathrm{mg} / \mathrm{kg}\right.$, i.p.), replicated the results, whereas pretreatment with a $5-\mathrm{HT}_{1 \mathrm{~A}}$-specific antagonist, 4 -iodo- $\mathrm{N}$-[2[4(methoxyphenyl)-1-piperazinyl] ethyl]- $\mathrm{N}$-2-pyridinyl-benzamide ( $3 \mathrm{mg} / \mathrm{kg}$, i.p.) given $20 \mathrm{~min}$ before 8-OH DPAT negated the effect of 8-OH DPAT. These results imply a potential clinical use of 5- $\mathrm{HT}_{1 \mathrm{~A}}$ agonists for post-SCI respiratory disorders.

Key words: spinal cord injury; cervical; hemicontusion; respiration; serotonin 1A; buspirone

\section{Introduction}

Respiratory disorders are the leading cause of morbidity and mortality after spinal cord injury (SCI), affecting approximately half of all patients with a neurological deficit after SCI (Winslow and Rozovsky, 2003). Respiratory impairments resulting from cervical SCI, the most common clinical case, frequently render survivors chronically or permanently ventilator dependent, a sequela that can dramatically compromise quality of life (Winslow and Rozovsky, 2003). However, respiratory abnormalities after cervical injuries have not been studied in conscious animal models, and there are no drug treatments for breathing disorders of SCI.

We reported previously that respiratory dysfunction after SCI is partly attributable to loss of the motoneurons innervating respiratory muscles (Teng et al., 1999). This was demonstrated in a thoracic

\footnotetext{
Received Sept. 28, 2004; revised March 28, 2005; accepted March 30, 2005.

This work was supported by the United Spinal Association, Veterans Affairs (VA) Biomedical Research Grant VA B29580, National Institutes of Health Grant 1-R01 NS40822, the Foundation for Physical Medicine and Rehabilitation (FPM\&R), and Project Amyotrophic Lateral Sclerosis. H.C. is a graduate of the VA Advanced Spinal Cord Injury Medicine Fellowship and a recipient of the FPM\&R New Investigator Award. We declare that we have no competing financial interests.

Correspondence should be addressed to Dr. Yang D. Teng, 300 Longwood Avenue, Bader 3, Boston, MA 02115. E-mail:yang_teng@hms.harvard.edu.

DOI:10.1523/JNEUROSCI.5135-04.2005

Copyright $\odot 2005$ Society for Neuroscience $\quad$ 0270-6474/05/254550-10\$15.00/0
}

vertebra 8 (T8) SCI rat model, in which acute treatment with basic fibroblast growth factor (bFGF) mitigated respiratory motoneuron loss and consequently preserved respiratory function. Unfortunately, only a very limited therapeutic window for strategies to reduce post-SCI motoneuron loss exists because of rapid postinjury neuronal degeneration (Teng et al., 1998, 1999). After T8 SCI, death of ventral motoneurons is completed within 4-24 h after SCI, and bFGF has to be given within 5 min after injury (Teng et al., 1998, 1999; Grossman et al., 2001). Considering that $90 \%$ of SCIs are initially incomplete, we subsequently designed an alternative therapeutic approach with the aim of enhancing the function of surviving respiratory motoneurons using serotonin $1 \mathrm{~A}\left(5-\mathrm{HT}_{1 \mathrm{~A}}\right)$ agonists (Teng et al., 2003). This group of agents was recently identified as respiratory stimulants that can counteract respiratory disturbances produced by hypoxia, morphine overdose, or obstructive sleep apnea (Mendelsohn et al., 1991; Lalley et al., 1994; Sahibzada et al., 2000). Administration of 8 -hydroxy-2-(di- $n$-propylmino)tetralin (8-OH DPAT), the prototypical $5-\mathrm{HT}_{1 \mathrm{~A}}$-specific agonist, restored respiratory frequency $(f)$, tidal volume $(\mathrm{Vt})$, and minute ventilation (Ve) to pre-SCI levels in T8 SCI rats (Teng et al., 2003). These data suggested that stimulation of surviving respiratory motoneurons via systemic $5-\mathrm{HT}_{1 \mathrm{~A}}$ agonists might become a novel therapy to improve post-SCI respiration. 
Agonists of 5- $\mathrm{HT}_{1 \mathrm{~A}}$ receptors have yet to be tested in animal models that closely emulate pathophysiology derived from cervical pathology commonly seen in clinical SCI. Of note, respiratory recovery in our T8 SCI model occurred consistently by $7 \mathrm{~d}$ after injury (Teng et al., 1999, 2003). Moreover, clinical SCI affects lower thoracic levels far less frequently than midcervical segments. The National Spinal Cord Injury Database (1993-1998) recorded that $47 \%$ of SCIs in the cohort were C4-C7 cases, with C5 carrying the greatest frequency (Go et al., 1995). We therefore hypothesized that a C5 hemicontusion model would adequately emulate the pathophysiology of clinical post-SCI respiratory dysfunction while offering practical surgical procedures, postinjury animal care, and survival rates appropriate for laboratory operations. We tested our hypothesis by using a well established wholebody plethysmography (WBP) system (Teng et al., 1999, 2003; Gray et al., 2001) and examined the therapeutic effects of 5- $\mathrm{HT}_{1 \mathrm{~A}}$ agonists in conscious post-SCI rats.

\section{Materials and Methods}

Spinal cord hemicontusion injury. A $3.0 \mathrm{~mm}$ left-sided hemilaminectomy encompassing the caudal end of vertebral level C4 and the rostral end of vertebral level C5 was produced in female Sprague Dawley rats (236-298 g; Charles River Laboratories, Wilmington, MA) after anesthesia with intraperitoneal ketamine $(75 \mathrm{mg} / \mathrm{kg})$ and xylazine $(10 \mathrm{mg} / \mathrm{kg})$. We used the New York University (NYU) impactor, a standardized device for delivery of contusive SCI in rats (Gruner, 1992), to produce an incomplete hemicontusive injury at the $\mathrm{C} 5$ spinal cord level from a height of $12.5 \mathrm{~mm}$ (mild SCI; $n=12$ ), $25 \mathrm{~mm}$ (moderate SCI; $n=13$ ), or $50 \mathrm{~mm}$ (severe SCI; $n=16$ ). Additional animals were given laminectomies only without SCI $(n=10)$ or no surgery and anesthesia at all $(n=9)$. We provided postoperative care as described previously (Teng et al., 1999, 2004).

Monitoring of respiratory parameters by plethysmography. Before baseline preoperative respiratory recordings, rats initially completed plethysmograph chamber acclimation training as described previously (Teng et al., 1999, 2003). In addition, a 20 min acclimation phase in the chamber preceded all initial respiratory data acquisition sessions for each rat. After acclimation, rats remained quietly in the chamber, allowing for the acquisition of data without physical signs of stress (e.g., defecation, urination). Respiratory data were measured noninvasively in unanesthetized, conscious, unrestrained, spontaneously breathing rats using a bias flowventilated WBP designed for rodents (PLY3213; Buxco Electronics, Wilmington, NC) (Gray et al., 2001). We used the Epstein barometric method to derive lung ventilation parameters from pressure fluctuations within chambers of fixed volume (Epstein et al., 1980). Pressure changes in the chamber were captured by a differential pressure transducer, amplified, and integrated by a software program (Biosystem XA 2.7.9; Buxco Electronics, Wilmington, NC) into volumes. A negative bias flow regulator, set to $1.5 \mathrm{~L} / \mathrm{min}$, ensured that fresh room air or alternatively concentrated $\mathrm{CO}_{2}$ gas was steadily supplied into the chambers and that $\mathrm{CO}_{2}$ from breaths expired from the animal did not accumulate. Hypercapnic gas mixtures contained either $7 \% \mathrm{CO}_{2}, 90 \% \mathrm{O}_{2}$, and $\mathrm{N}_{2}$ balance or $5 \%$ $\mathrm{CO}_{2}, 90 \% \mathrm{O}_{2}$, and $\mathrm{N}_{2}$ balance. Hyperoxic (i.e., $90 \% \mathrm{O}_{2}$ ) gas was used to ensure that the brief respiratory drive surges were initiated by hypercarbia in our long-term studies (i.e., not from hypoxia that also affects the respiratory system) (Feldman et al., 2003). Respiratory parameters from the current study were all within ranges similar to those our laboratory reported previously in which $60 \% \mathrm{O}_{2}$ was used (Teng et al., 1999, 2003). Periods when subjects were moving around in the plethysmograph chamber, sniffing, grooming, or otherwise not in a mode of quiet conscious breathing were marked by trained observers during data collection and were excluded from analysis (Teng et al., 1999, 2003; Gray et al., 2001; Stephenson and Gucciardi, 2002).

Drug administration. The 5- $\mathrm{HT}_{1 \mathrm{~A}}$-specific agonists 8-OH DPAT (Tocris Cookson, Ellisville, MO) and buspirone (Sigma, St. Louis, MO) were dissolved in $0.9 \%$ saline (adjusted to $\mathrm{pH} 7.4$ ) and administered intraperitoneally in $0.5 \mathrm{ml}$ of final injection volume per rat at doses of 125 or 250 $\mu \mathrm{g} / \mathrm{kg}$ for 8-OH DPAT and $1.5 \mathrm{mg} / \mathrm{kg}$ for buspirone (Teng et al., 2003). The $5-\mathrm{HT}_{1 \mathrm{~A}}$ receptor-specific antagonist 4-iodo- $\mathrm{N}$-[2-[4-methoxyphenyl)-1-piperazinyl] ethyl]- $N$-2-pyridinyl-benzamide ( $p$-MPPI) (Sigma St. Louis, MO) was dissolved in $0.9 \%$ saline and given intraperitoneally at a dose of $3 \mathrm{mg} / \mathrm{kg}$, pH 7.4 (final volume, $0.5 \mathrm{ml}$ ), before 8-OH DPAT administration (Teng et al., 2003).

Neurobehavioral studies. The forelimb functional test was done by using a modified Tarlov scale ranging from 0 (no movement) to 5 (normal, weight-bearing forelimb use) as described previously (Gale et al., 1985). To measure hindlimb function, we modified the Basso-Beattie-Bresnahan (BBB) scoring process (the BBB scale ranges from 0 to 21 , where 0 indicates total hindlimb paralysis and 21 indicates normal performance) (Basso et al., 1995) by referencing hindlimb movements on the injured side only with those of the forelimb on both the uninjured and injured sides to obtain scores of coordination resulting from dysfunction in the forepaw ipsilateral to the hemicontusion SCI. Because forelimb movement of the injured side alone was not precise enough to evaluate stepping, the intact side forelimb was used as a reference to best judge whether the affected hindlimb moved in combination with the ipsilateral forelimb (i.e., coordination; rats move ipsilateral forelimb and hindlimb simultaneously). Neurobehavioral scores for both the hemicontused and contralateral sides were recorded by two evaluators blinded to the injury doses of the experimental groups.

Histopathology. Rats for histopathological analysis were terminated at 4 weeks after SCI ( $n=4$ per group; i.e., mild, moderate, severe, or no hemicontusion injury) using intracardiac perfusion with $0.1 \mathrm{M}$ phosphate buffer and $4 \%$ paraformaldehyde as described previously (Teng et al., 1999, 2003). Spinal cord histopathology using cresyl violet and solvent blue/hematoxylin and eosin stains were performed as described previously (Teng et al., 2004) to evaluate the dimensions and anatomical profiles of the lesion volume and to evaluate postcontusion motoneuronal loss (Noble and Wrathall, 1989; Teng et al., 1998). All experiments were conducted in strict compliance with the Laboratory Animal Welfare Act and the National Institutes of Health Guide for the Care and Use of Laboratory Animals after approval by the Animal Care and Use Committee of the Veterans Affairs Boston Healthcare System.

Experimental protocol. A total of 60 animals were used for this study. After 1 week of plethysmograph chamber acclimation training (Teng et al., 1999), preoperative baseline respiratory recording was performed for each rat in room air and $7 \% \mathrm{CO}_{2}$. SCI surgery for rats in the surgical groups was performed $24 \mathrm{~h}$ after baseline respiratory recording. Postoperative respiratory and neurobehavioral studies were performed at $1 \mathrm{~d}$ after SCI and then at 1, 2, 3, 4, and 6 weeks after SCI. At each WBP session, respiratory parameters, including $f, \mathrm{Vt}$, and Ve were collected for 5 min during room air ventilation. Each animal was then exposed to a gas mixture containing $7 \% \mathrm{CO}_{2}$ for $7 \mathrm{~min}$, and the same parameters were recorded. At the 2 week post-SCI period, we performed a separate study for all rats using $5 \% \mathrm{CO}_{2}$ to confirm a respiratory dose-response to hypercapnia [i.e., to compare respiratory parameters under $0.03 \%$ (room air), $5 \%$, and $7 \% \mathrm{CO}_{2}$ ]. As described previously, only the last 2 min of data during either 5 or $7 \%$ hypercapnic challenge was used for analysis (Teng et al., 1999).

At $5 \mathrm{~d}$ after SCI, four randomly selected rats with severe hemicontusion SCI underwent a washout (i.e., a transformed dose-response) study of the respiratory effect of $8-\mathrm{OH}$ DPAT $(250 \mu \mathrm{g} / \mathrm{kg}$, i.p.). Respiratory parameters in room air (for $5 \mathrm{~min}$ ) and under $7 \% \mathrm{CO}_{2}(7 \mathrm{~min}$, with the last $2 \mathrm{~min}$ used for data analysis) were recorded $15 \mathrm{~min}$ after an intraperitoneal 8-OH DPAT injection, with the $12 \mathrm{~min}$ (5 plus $7 \mathrm{~min}$ ) recording period repeated at the end of every consecutive hour for up to $5 \mathrm{~h}$ as described previously (Teng et al., 2003). Studies to evaluate the effects of 8 -OH DPAT $(250 \mu \mathrm{g} / \mathrm{kg})$ across injury dose groups were performed at 2 and 4 weeks after SCI in subgroups of rats randomly sampled from each uninjured and hemicontused group (mild, $n=9$; moderate, $n=9$; severe, $n=12$; uninjured controls, $n=13$ ). Rats were allowed to rest at least $60 \mathrm{~min}$ in room air before being injected intraperitoneally with 8-OH DPAT $(250 \mu \mathrm{g} / \mathrm{kg})$. After a $15 \mathrm{~min}$ postinjection period, room air respiratory data were recorded for $5 \mathrm{~min}$. Immediately after room air recording, each rat was then exposed to $7 \% \mathrm{CO}_{2}$ for $7 \mathrm{~min}$, and the last 2 min were used for data analysis. 
Twelve rats in the severely injured group underwent additional testing with buspirone $(1.5 \mathrm{mg} / \mathrm{kg}), p$-MPPI $(3 \mathrm{mg} / \mathrm{kg})$, and a lower dose of 8 -OH DPAT ( $125 \mu \mathrm{g} / \mathrm{kg}$ ) separately. Because of the large number of tests performed at the 2 week post-SCI period and the lengthy waiting periods necessary to washout $8-\mathrm{OH}$ DPAT, these tests were randomly divided over a $3 \mathrm{~d}$ period that corresponded to days $13-15$ after SCI. We delivered p-MPPI 20 min before 8-OH DPAT injection and recorded 5 min of room air respiratory data $5 \mathrm{~min}$ after the $p$-MPPI injection. Fifteen minutes after the 8-OH DPAT injection, respiratory parameters were recorded in room air for $5 \mathrm{~min}$, followed by $7 \% \mathrm{CO}_{2}$ for $7 \mathrm{~min}$. Respiratory parameters were recorded $15 \mathrm{~min}$ after buspirone $(1.5 \mathrm{mg} / \mathrm{kg}$, i.p.) injection.

Statistics. Respiratory study data for the overall C5 hemicontusion model were analyzed by a generalized linear model (GLM) resulting from dissimilarities in the number of observations per subject (i.e., some rats were terminated at 4 weeks for histopathological study), constraining the use of standard ANOVA techniques (Kleinbaum et al., 1998). Post hoc linear regression was performed when general analysis showed a significant difference. The dependent variables were $f, \mathrm{Vt}$, and $\mathrm{Ve}$, whereas injury dose, body weight, and $\mathrm{CO}_{2}$ level were tested as predictors. Nonlongitudinal multiple linear regression was used to examine short-term changes in $f$ during the acute post-SCI period. To examine the effects of the pharmacological agents, respiratory parameters were compared using repeated-measures ANOVA, with post hoc Tukey's test (Teng et al., 2003). Correlations between Ve at the time the animals were killed and lesion size or motoneuronal counts were examined using Pearson correlation. Correlations between injury dose and lesion size or motoneuronal counts were examined using Spearman correlation. Statistics were performed using the STATA 8.2 statistical package (StataCorp, College Station, TX). We considered differences in data to be significant when $p<$ 0.05 . All interventions and primary data collection were performed in a blinded manner.

\section{Results \\ C5 hemicontusion SCI produces lesion dose-dependent respiratory deficits}

Clinical studies have revealed that deficits in post-SCI respiratory parameters correlate with injury severity (Linn et al., 2001). We therefore subjected rats to varying grades of contusive SCI at the C5 level, delegated as mild $(10 \mathrm{~g} \times 12.5 \mathrm{~mm} ; n=12)$, moderate $(10 \mathrm{~g} \times 25 \mathrm{~mm} ; n=13)$, or severe $(10 \mathrm{~g} \times 50 \mathrm{~mm}, n=16)$ injury using an NYU impactor (Gruner, 1992). Because midline cervical SCI in rats dramatically impairs respiration and food procurement to cause very poor postoperative survival, we administered a left-sided hemicontusion injury. In anticipation of potentially greater morbidity and mortality in groups receiving more severe injury doses, we assigned higher numbers of subjects to these groups. Only one rat each in the moderate and severely injured groups died postoperatively, however, with subsequent removal of their data from the study. Control rats received C5 left hemilaminectomy only without SCI $(n=10)$ or no surgery $(n=9)$.

To avoid the potential artifacts stemming from physical restraints (Teng et al., 1999, 2003), anesthesia (Teng and Wrathall, 1996), or instrumentation (Teng and Wrathall, 1996), we measured respiratory parameters noninvasively in conscious, spontaneously breathing rats using WBP after sufficient acclimation (Fig. 1) (Teng et al., 1999, 2003). Respiratory parameters (i.e., $f$, $\mathrm{Vt}$, and $\mathrm{Ve}$ ) for controls and for rats before surgery in room air and under hypercapnic conditions (data not shown) were consistent with the literature (Lai et al., 1978; Teng et al., 1999, 2003). No significant differences in body weight or respiratory function recordings were detected between the group that received C5 hemilaminectomy only and the nonoperative group at any time point (data not shown), and their data were therefore combined to form a single control group $(n=19$; Teng et al., 1998). Body weights in rats with hemicontusion injury decreased during the
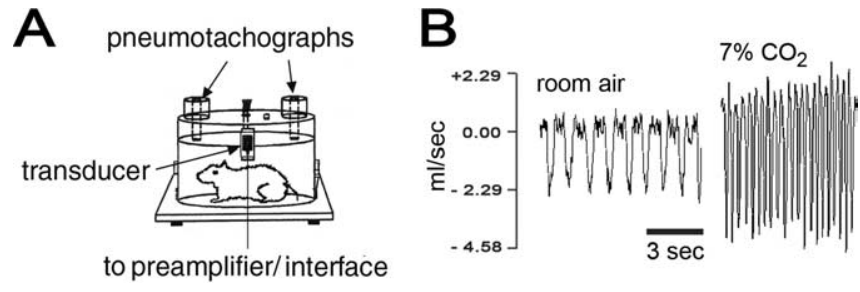

Figure 1. Noninvasive measurement of respiratory function in conscious rats using WBP. $A$, Diagram of a fixed-volume $(3.9 \mathrm{~L}$ ) plethysmograph chamber for WBP testing of unrestrained conscious rats. After acclimation, rats remained calm within the chambers for prolonged periods (up to $5 \mathrm{~h}$ ). $\boldsymbol{B}$, WBP flow tracings ( $\mathrm{ml} / \mathrm{s}$ ) of an uninjured rat exposed to room air (left) and $7 \%$ $\mathrm{CO}_{2}$ (right). The tracings were converted to respiratory parameters such as $f, \mathrm{Vt}$, and Ve by software.

initial post-SCI period in correlation with injury dose (e.g., $|r|=$ $0.616 ; p<0.001$ at 7 d; Spearman correlation) (Fig. $2 A$ ). By week 6 after SCI, there was only a weak correlation between body weight and injury dose $(|r|=0.255 ; p=0.024$; Spearman correlation); rats given mild or moderate injury recovered their body weights to levels comparable with controls.

Primary data analysis using a GLM revealed that lesion dose (i.e., uninjured controls or mild, moderate, or severe hemicontusion injury) had a significant effect on $\mathrm{Vt}$ and $\mathrm{Ve}(p<0.001)$, but not $f(p=0.116)$, over the 6 week post-SCI course (Table 1$)$. Importantly, post hoc multiple linear regression analyses showed that groups receiving hemicontusion injury had a statistically significant injury dose-dependent reduction of Vt during room air exposure during the first 2 weeks after injury ( $p \leq 0.037$ ) (Fig. $2 B$, Table 1). Additionally, the data revealed a lesion dosedependent posthemicontusion increase in room air $f$, resulting in a shallow, rapid breathing pattern during the first 2 weeks after injury ( $p \leq 0.044$; GLM with post hoc multiple linear regression) (Table 1), which was consistent with our previous reports (Teng et al., 1999, 2003). Room air ventilatory parameters ( $f$, Vt, and $\mathrm{Ve}$ ) in hemicontused rats recovered to levels not statistically different from controls 2 weeks after injury.

To document respiratory dysfunction of a more chronic nature, rats were also challenged with $7 \% \mathrm{CO}_{2}$. Hypercapnic challenge has been demonstrated to elicit respiratory deficits with greater sensitivity than room air experimentally (Teng et al., 1999, 2003; Golder et al., 2001). Moreover, profoundly reduced $\mathrm{Vt}, f$, and Ve responses to hypercapnia have been well documented in chronic tetraplegics in the clinical literature (Manning et al., 1992). We found a significantly diminished ability in hemicontused rats to augment $\mathrm{Vt}$ when challenged by $7 \% \mathrm{CO}_{2}$ that was injury dose dependent ( $p \leq 0.007$; GLM with post hoc multiple linear regression), resulting in a severely mitigated Ve response during the first 4 weeks after SCI ( $p \leq 0.031$; GLM with post hoc multiple linear regression) (Table 1). For instance, there was a $24.8 \%$ decrease in hypercapnic Ve in severely injured rats at 2 weeks after SCI and a $13.5 \%$ decrease at 4 weeks after SCI compared with uninjured controls. Moreover, there was a clear injury dose-related trend in the loss of the ability to augment $f$ when breathing 7\% $\mathrm{CO}_{2}$ ( $p \leq 0.063 \mathrm{GLM}$ with post hoc multiple linear regression). Overall, these data indicated that there were injury dose-dependent chronic abnormalities in the post-SCI respiratory parameters in our C5 hemicontusion model.

\section{Respiratory deficits after $\mathrm{C} 5$ hemicontusion SCI correlate with lesion pathology}

At 4 weeks after SCI, rats with behavioral scores representative of the corresponding group average were selected from each study 

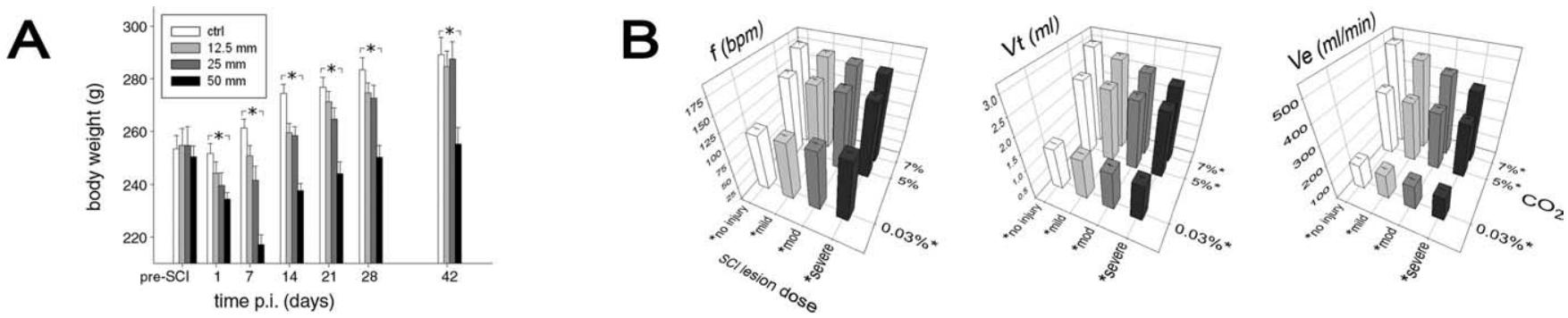

Figure 2. More severe grades of $\mathrm{C} 5$ hemicontusion injury resulted in greater loss of postinjury body weight and higher degrees of respiratory dysfunction. $A$, The effect of lesion dose (uninjured control vs $12.5,25$, or $50 \mathrm{~mm}$ (5 hemicontusion injury) is shown to correlate inversely with body weight during the 6 week post- $\mathrm{SCl}$ course. Note that rats with $50 \mathrm{~mm}$ injuries did not recover to control levels, even after 6 weeks ( ${ }^{*} p<0.05$; Spearman correlation). ctrl, Control; p.i., postinjury. B, Representative ventilatory parameters at 2 weeks after $\mathrm{SCl}$ versus uninjured controls. Error bars represent SEM. ${ }^{*} p<0.05 ; \mathrm{GLM}$, post hoc multiple linear regression. mod, Moderate injury. Left, Respiratory frequency as a function of lesion dose (uninjured control vs $12.5,25,0 \mathrm{~m} 50 \mathrm{~mm} C 5$ hemicontusion injury) and $\mathrm{CO}_{2}$ exposure (room air, $5 \% \mathrm{CO}_{2}$, or $\left.7 \% \mathrm{CO}_{2}\right)$. The $\mathrm{CO}_{2}$ level was a significant covariate across all lesion dose groups ( $\left.p<0.001\right)$. Lesion dose was a significant covariate during room air ventilation ( $p=0.037$ ). Rats with more severe lesions had a tendency for greater resting respiratory frequency while breathing room air but had a diminished augmentation of response to hypercapnic stimulus. Middle, Tidal volume as a function of lesion dose and $\mathrm{CO}_{2}$ exposure. The $\mathrm{CO}_{2}$ level was a significant covariate across all lesion dose groups $(p<0.001)$. Lesion dose was a significant covariate during room air ventilation and $5 \%$ and $7 \% \mathrm{CO}_{2}$ ventilation $(p \leq 0.017)$. Right, Minute ventilation as a function of lesion dose and $\mathrm{CO}_{2}$ exposure. The $\mathrm{CO}_{2}$ level was a significant covariate across all lesion dose groups ( $p<0.001)$. Rats with all grades of $(5$ hemicontusion injury, resulting from a combination of higher fand diminished Vt, had resting Ve similar to those of controls while breathing room air. When challenged with hypercapnic stimulus, rats with $C 5$ hemicontusion injury displayed a lesion dose-dependent diminished augmentation of minute ventilation response compared with uninjured controls ( $p=0.035$ at $5 \% \mathrm{CO}_{2} ; p<0.001$ at $\left.7 \% \mathrm{CO}_{2}\right)$.

Table 1. Lesion dose-dependent respiratory parameters after $\mathrm{C5}$ hemicontusion $\mathrm{SCI}$

\begin{tabular}{|c|c|c|c|c|c|c|c|c|c|c|c|}
\hline \multirow[b]{2}{*}{ Injury dose } & \multicolumn{2}{|l|}{ Day 1} & \multicolumn{2}{|l|}{ Week 1} & \multicolumn{3}{|l|}{ Week 2} & \multicolumn{2}{|l|}{ Week 4} & \multicolumn{2}{|l|}{ Week 6} \\
\hline & $0.03 \% \mathrm{CO}_{2}$ & $7 \% \mathrm{CO}_{2}$ & $0.03 \% \mathrm{CO}_{2}$ & $7 \% \mathrm{CO}_{2}$ & $0.03 \% \mathrm{CO}_{2}$ & $5 \% \mathrm{CO}_{2}$ & $7 \% \mathrm{CO}_{2}$ & $0.03 \% \mathrm{CO}_{2}$ & $7 \% \mathrm{CO}_{2}$ & $0.03 \% \mathrm{CO}_{2}$ & $7 \% \mathrm{CO}_{2}$ \\
\hline \multicolumn{12}{|l|}{$f(\mathrm{bpm})$} \\
\hline $12.5 \mathrm{~mm}$ & $112.8 \pm 1.5$ & $160.6 \pm 2.0$ & $112.0 \pm 2.0$ & $163.2 \pm 2.2$ & $108.7 \pm 1.8$ & $144.2 \pm 2.6$ & $170.4 \pm 2.4$ & $106.1 \pm 1.7$ & $173.6 \pm 2.9$ & $101.6 \pm 1.5$ & $180.7 \pm 3.0$ \\
\hline $25 \mathrm{~mm}$ & $122.5 \pm 1.6$ & $148.7 \pm 2.9$ & $116.0 \pm 2.2$ & $154.9 \pm 2.4$ & $112.2 \pm 1.9$ & $143.2 \pm 2.6$ & $166.1 \pm 2.6$ & $108.1 \pm 3.3$ & $168.6 \pm 3.2$ & $104.0 \pm 1.7$ & $182.6 \pm 3.4$ \\
\hline \multirow[t]{2}{*}{$50 \mathrm{~mm}$} & $132.2 \pm 2.4$ & $136.9 \pm 4.4$ & $120.0 \pm 3.6$ & $146.6 \pm 3.9$ & $115.7 \pm 3.1$ & $142.1 \pm 4.2$ & $161.7 \pm 4.3$ & $103.0 \pm 3.1$ & $163.6 \pm 5.2$ & $106.3 \pm 2.7$ & $184.5 \pm 5.4$ \\
\hline & $p<0.001^{\dagger}$ & $p<0.001^{\dagger}$ & $p=0.044^{\dagger}$ & $p<0.001^{\dagger}$ & $p=0.037^{\dagger}$ & $p=0.651$ & $p=0.057$ & $p=0.771$ & $p=0.063$ & $p=0.084$ & $p=0.476$ \\
\hline $12.5 \mathrm{~mm}$ & $1.24 \pm 0.02$ & $2.36 \pm 0.04$ & $1.28 \pm 0.02$ & $2.58 \pm 0.05$ & $1.30 \pm 0.02$ & $2.29 \pm 0.04$ & $2.78 \pm 0.04$ & $1.46 \pm 0.02$ & $2.98 \pm 0.04$ & $1.49 \pm 0.02$ & $3.15 \pm 0.04$ \\
\hline $25 \mathrm{~mm}$ & $1.14 \pm 0.02$ & $1.98 \pm 0.04$ & $1.25 \pm 0.02$ & $2.41 \pm 0.05$ & $1.25 \pm 0.02$ & $2.20 \pm 0.04$ & $2.59 \pm 0.04$ & $1.44 \pm 0.02$ & $2.89 \pm 0.04$ & $1.47 \pm 0.02$ & $3.10 \pm 0.05$ \\
\hline $50 \mathrm{~mm}$ & $1.02 \pm 0.03$ & $1.60 \pm 0.06$ & $1.18 \pm 0.04$ & $2.24 \pm 0.09$ & $1.22 \pm 0.03$ & $2.12 \pm 0.06$ & $2.40 \pm 0.06$ & $1.43 \pm 0.04$ & $2.79 \pm 0.07$ & $1.44 \pm 0.04$ & $3.04 \pm 0.07$ \\
\hline \multirow[t]{2}{*}{ Adjusted $r^{2}$} & 0.432 & 0.784 & 0.196 & 0.375 & 0.150 & 0.249 & 0.424 & 0.092 & 0.332 & 0.124 & 0.092 \\
\hline & $p<0.001^{*}$ & $p<0.001^{*}$ & $p=0.028^{*}$ & $p=0.001^{*}$ & $p=0.017^{*}$ & $p=0.017^{*}$ & $p<0.001^{*}$ & $p=0.477$ & $p=0.007^{*}$ & $p=0.194$ & $p=0.165$ \\
\hline \multicolumn{12}{|l|}{ Ve $(\mathrm{m} / \mathrm{min})$} \\
\hline \multirow[t]{2}{*}{ Adjusted $r^{2}$} & 0.025 & 0.737 & 0.029 & 0.434 & 0.026 & 0.216 & 0.374 & 0.029 & 0.146 & 0.002 & 0.038 \\
\hline & $p=0.475$ & $p<0.001^{*}$ & $p=0.335$ & $p<0.001^{*}$ & $p=0.952$ & $p=0.035^{*}$ & $p<0.001^{*}$ & $p=0.669$ & $p=0.031^{*}$ & $p=0.429$ & $p=0.568$ \\
\hline
\end{tabular}

Respiratory frequency (bpm, breaths per minute), tidal volume, and minute ventilation measured by WBP in conscious, unrestrained rats with no SCI ( $n=19)$ or after 12.5 ( $n=12), 25$ ( $n=12)$, or 50 ( $n=15)$ mm $(5$ hemicontusion injury ( $\times 10 \mathrm{~g}$; NYU impactor) at $1 \mathrm{~d}$ and $1,2,4$, and 6 weeks after SCl in room air $\left(0.03 \% \mathrm{CO}_{2}\right)$ and under hypercapnic conditions ( 5 or $7 \% \mathrm{C}_{2}$ plus $90 \% 0_{2}$ and $\mathrm{N}_{2}$ balance). Week 3 data did not differ significantly from week 4 data and are not presented. Four rats from each group were killed after collection of respiratory data at week 4 for histological studies; thus, week 6 data represent $15,8,8$, and 11 animals for the control, $12.5,25$, and $50 \mathrm{~mm}$ groups, respectively. All parameters represent means (corrected by linear regression for group differences in body weight) \pm SE of the linear prediction of the mean. The asterisk indicates primary GLM positive ( $p<0.05 ;$; 0 st hoc linear regression). The dagger symbol indicates nonlongitudinal multiple linear regression $(p<0.05)$.

group (i.e., mild, moderate, severe, or no hemicontusion; $n=4$ per group) for histopathological analysis of the spinal cords (Teng et al., 1999, 2004). This end number had been determined adequate for functional data analysis resulting from the high consistency in our data collection (Teng et al., 1999, 2003). All rats undergoing histopathological analysis received 8-OH DPAT (250 $\mu \mathrm{g} / \mathrm{kg}$, i.p.) at 2 and 4 weeks after injury and buspirone (1.5 $\mathrm{mg} / \mathrm{kg}$, i.p.) and $p$-MPPI ( $3 \mathrm{mg} / \mathrm{kg}$, i.p.) at 2 weeks after injury while undergoing respiratory studies. In addition, the severely injured rats received $8-\mathrm{OH}$ DPAT $(250 \mu \mathrm{g} / \mathrm{kg})$ at $5 \mathrm{~d}$ after SCI for the dose washout study and 8-OH DPAT $(125 \mu \mathrm{g} / \mathrm{kg})$ at 2 weeks after SCI during the dose-response study. For general lesion morphology, we examined transverse sections of spinal cord at the C5 epicenter of hemicontusion injury and in $1 \mathrm{~mm}$ increments rostral and caudal to the epicenter that were stained with solvent blue/hematoxylin and eosin (Teng et al., 2004) (Fig. 3A). The cross-sectional profiles of injury epicenters of rats with severe hemicontusion injuries were characterized by the occasional presence of the most peripheral elements of gray matter, as well as a peripheral, often incomplete, rim of residual hypomyelinated white matter in the affected half spinal cord (Fig. 3A5). White matter degeneration at the epicenter included the ventrolateral, ventral, and medial funiculi, which are important descending respiratory pathways in the rat (Newsom Davis and Plum, 1972), the ventromedial white matter, which is the most critical region for hindlimb locomotion in rats (Blight, 1983), and the basal part of the dorsal column, a sector that houses the rat corticospinal tract, which is crucial in controlling precise forelimb movement (Raineteau et al., 2001). Injury dose-dependent areas of white and gray matter pathology extended up to $3 \mathrm{~mm}$ rostral and 

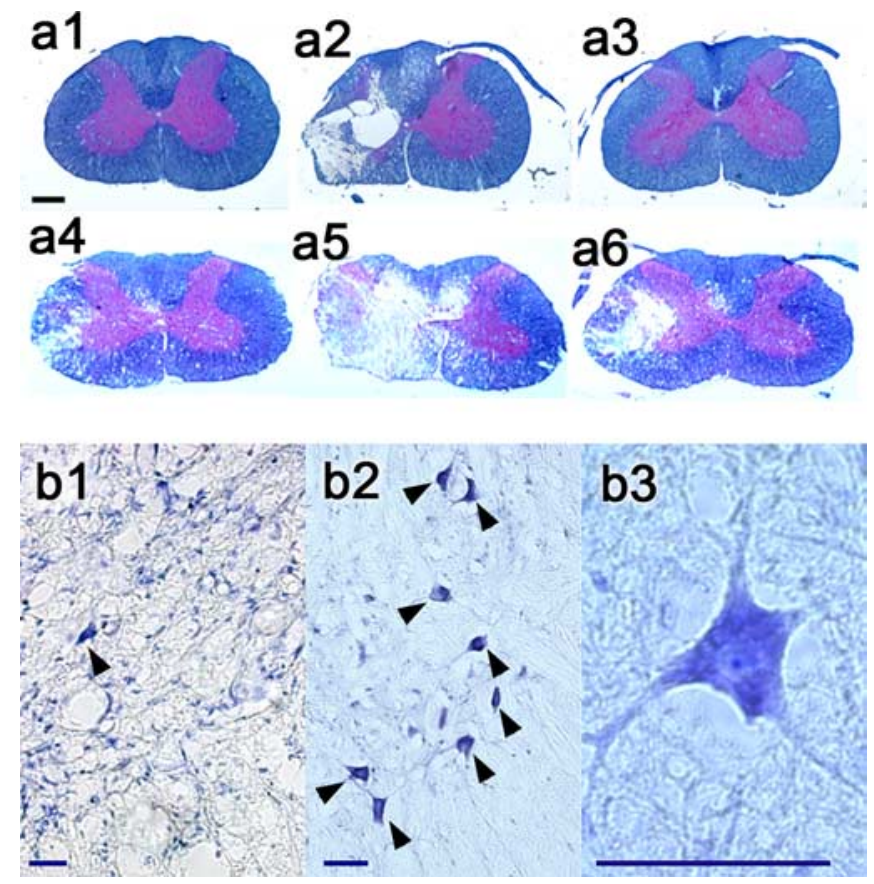

Figure 3. Histopathological changes after $(5$ hemicontusion injury. $\boldsymbol{a}$, Solvent blue plus hematoxylin and eosin transverse sections $2 \mathrm{~mm}$ rostral from the epicenter $(\boldsymbol{a 1}, \boldsymbol{a} 4)$, at the epicenter $(\boldsymbol{a} \mathbf{2}, \boldsymbol{a} \mathbf{5})$, and $2 \mathrm{~mm}$ caudal from the epicenter $(\boldsymbol{a} \mathbf{3}, \boldsymbol{a} \mathbf{6})$ in rats representative of mild injury (top; $\boldsymbol{a} \mathbf{1 - a 3}$ ) and severe injury (bottom; $\boldsymbol{a} 4-\boldsymbol{a b}$ ) at 4 weeks after $\mathrm{SCl}$. Scale bar, (in a1) $500 \mu \mathrm{m} . \boldsymbol{b}$, Cresyl violet transverse sections $2 \mathrm{~mm}$ rostral to the epicenter in a representative severe hemicontusion injury (b1) at 4 weeks after $\mathrm{SCl}$ versus an uninjured control (b2) rat. Arrowheads indicate ventral motoneurons. $\boldsymbol{b} 3$, A representative ventral motoneuron (oil immersion) displaying Nissl substance, a euchromatic nucleus, and a distinct nucleolus. Scale bars: b1-b3, $20 \mu \mathrm{m}$.

caudal to the epicenter ( $r \geq 0.537 ; p \leq 0.028$; Spearman correlation), with partial involvement of the $\mathrm{C} 4$ and C6 levels in the most severe cases.

To explore whether neuronal loss is responsible for postinjury respiratory abnormalities (Teng et al., 1999), we stained the immediately adjacent transverse sections with cresyl violet $(n=13$; four uninjured controls and three of each injury severity). We observed an injury dose-dependent loss of ventral motoneurons ( $r \geq 0.768$; $p \leq 0.006$; Spearman correlation) (Fig. $3 B$ ) on the hemicontused side in each section up to $2 \mathrm{~mm}$ rostral and $1 \mathrm{~mm}$ caudal to the epicenter relative to controls. Note that the numbers of ventral motoneurons at $2 \mathrm{~mm}$ rostral to the epicenter on the hemicontused side or its corresponding counts in controls significantly correlated with Ve under $7 \% \mathrm{CO}_{2}$ at week 4 after injury ( $r=0.701 ; p=0.016$; Pearson correlation). Ventral motoneurons ipsilateral to the injury at this segment numbered from $8.8 \pm$ 1.9 (mean \pm SEM) in uninjured controls, $4.0 \pm 0.6$ in mildly injured animals, $3.3 \pm 1.5$ in moderately injured animals, to $1.3 \pm 0.7$ in the severely injured group. Ipsilateral motoneuronal counts in other transverse sections did not correlate with hypercapnic Ve before the animal was killed ( $p \geq 0.127$; Pearson correlation). Contralateral ventral motoneuronal counts were not significantly different in rats with hemicontusion injury compared with controls (on average, $8.4 \pm 0.4$ vs $9.4 \pm 0.7 ; p>0.05$; Student's $t$ test).

\section{Effect of C5 hemicontusion SCI on general somatic neurobehavioral function}

We recorded the neurobehavioral effects of our C5 hemicontusion model using modified Tarlov (Gale et al., 1985) and modi-

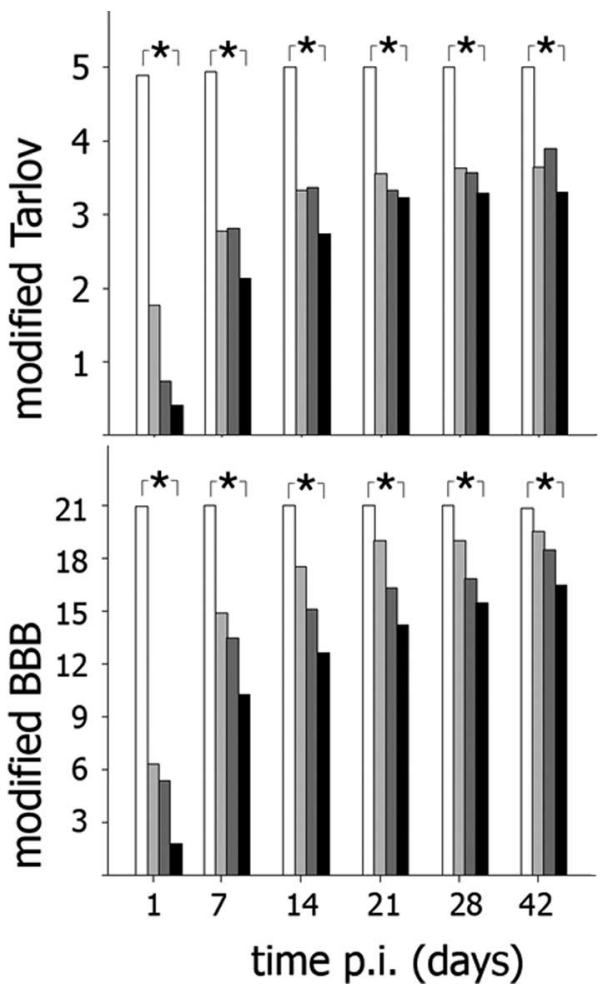

Figure 4. Forelimb and hindlimb neurobehavioral function declined after $\mathrm{C} 5$ hemicontusion injury in lesion dose-dependent manners. Top, Neurobehavioral function of the forelimb (measured by a modified Tarlov scale) on the side ipsilateral to the hemicontused spinal cord correlated inversely with lesion dose (uninjured control vs $12.5,25$, or $50 \mathrm{~mm}$ C5 hemicontusion injury) from $1 \mathrm{~d}$ to 6 weeks after $\mathrm{SCl}$ ( ${ }^{*} p<0.05$; Spearman correlation). Forelimb neurobehavioral function on the side opposite of the spinal cord hemicontusion recovered to preoperative levels during the first week after SCI. Bottom, Neurobehavioral function of the hindlimb (measured by a modified BBB scale) on the side ipsilateral to the hemicontused spinal cord correlated inversely with lesion dose (uninjured control vs $12.5,25$, or $50 \mathrm{~mm}$ (5 hemicontusion injury) from $1 \mathrm{~d}$ to 6 weeks after $\mathrm{SCl}$ ( ${ }^{*} p<0.05$; Spearman correlation). ctrl, Control; p.i., postinjury.

fied BBB scales (Basso et al., 1995) for the forelimbs and hindlimbs, respectively (Fig. 4). Forelimb and hindlimb neurobehavioral scores contralateral to the hemicontusion injury recovered to preoperative baselines during the first week after SCI. In contrast, ipsilateral locomotor function remained abnormal for all 6 weeks after injury. For the forelimb, there was a significant inverse correlation between injury dose and ipsilateral modified Tarlov scores at all time points from $1 \mathrm{~d}$ to 6 weeks after SCI $(r \leq-0.695 ; p<0.001$; Spearman correlation). Injury dose and ipsilateral hindlimb modified BBB scores were also inversely correlated at all time points from $1 \mathrm{~d}$ to 6 weeks after injury $(r \leq$ $-0.735 ; p<0.001$; Spearman correlation). Overall, these data demonstrated chronic somatomotor deficits in the ipsilateral forelimbs and hindlimbs, which did not recover to baseline preoperative levels even after 6 weeks after injury. Respiratory function, in contrast, improved to levels comparable with uninjured controls at 2 and 4 weeks after injury, in room air or hypercapnic ventilation, respectively.

\section{5-HT ${ }_{1 \mathrm{~A}}$ agonists ameliorate respiratory deficits resulting from} C5 hemicontusion SCI

Serotonin is well known to be a key modulator of respiration in the CNS (Zhou and Goshgarian, 2000; Fuller et al., 2005) (for review, see Mitchell and Johnson, 2003). In particular, agonists of the $5-\mathrm{HT}_{1 \mathrm{~A}}$ subreceptor have been shown to improve respiratory 

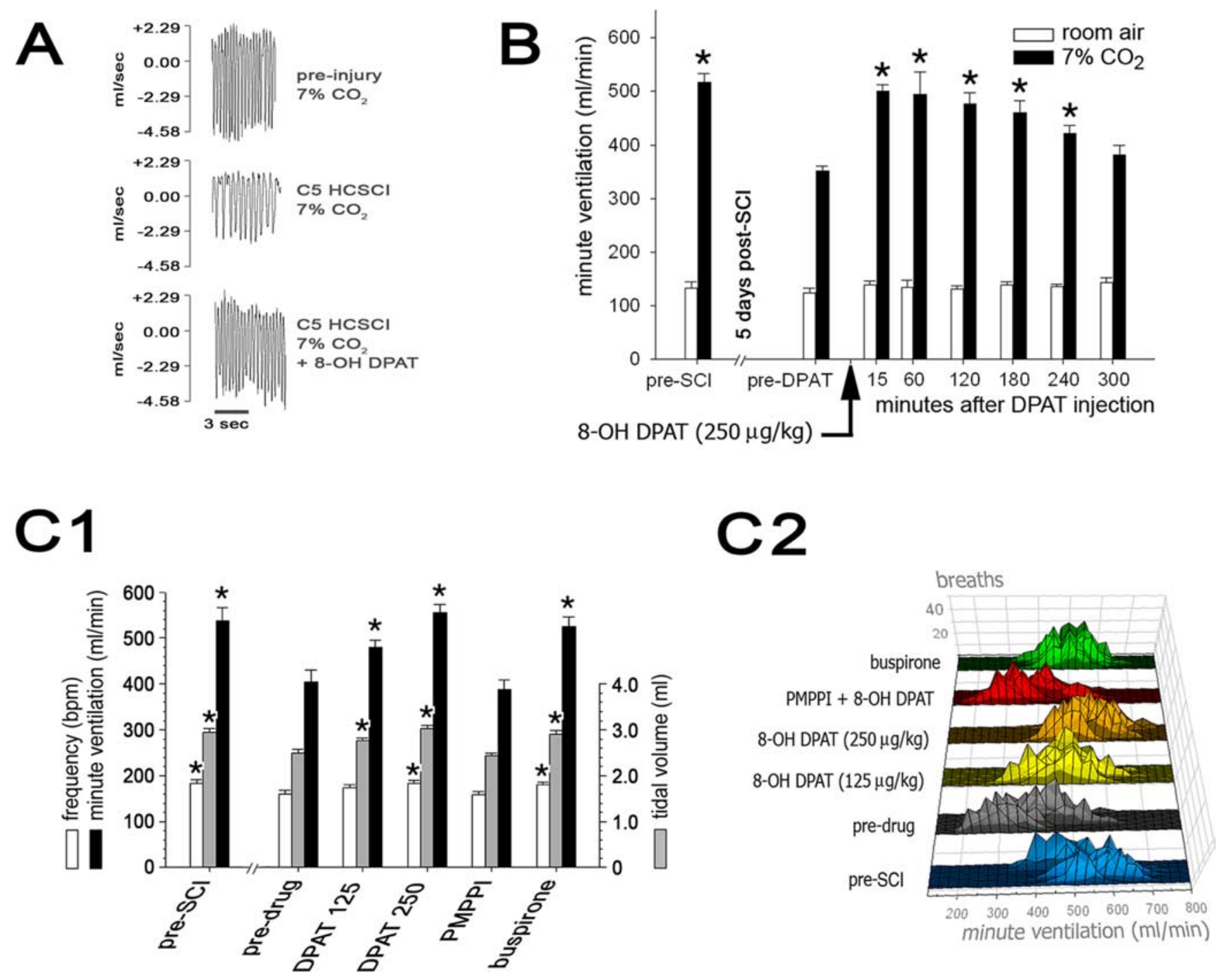

Figure 5. Effects of $5-\mathrm{HT}_{1 \mathrm{~A}}$ agents on minute ventilation in hypercapnic conditions after $(5$ hemicontusion injury. $A$, WBP respiratory flow tracings of a representative uninjured rat breathing $7 \%$ $\mathrm{CO}_{2}$ (top) and then breathing $7 \% \mathrm{CO}_{2} 2$ weeks after severe $\mathrm{C}_{5}$ hemicontusion injury ( $\mathrm{HCSCl}$ ) before (middle) and after administration of 8-OH DPAT (250 $\mu \mathrm{g} / \mathrm{kg}$, i.p.; bottom). B, The effects of 8-0H DPAT on Ve in rats $(n=4)$ with severe $(50 \mathrm{~mm})$ hemicontusion injury at $5 \mathrm{~d}$ after SCI. Systemic $8-0 \mathrm{H} \mathrm{DPAT}(250 \mu \mathrm{g} / \mathrm{kg})$ restored Ve responses to $7 \% \mathrm{CO}_{2}$ stimulus in severely injured rats to a level comparable with preinjury baseline, an effect that lasted up to $4 \mathrm{~h}$ after a single intraperitoneal dose ${ }^{*} p<0.05$, significantly different from predrug levels; repeated-measures ANOVA with post hoc Tukey's tests). (1, Effects of 5-HT 1 A agonists and antagonists on respiratory parameters at 2 weeks after SCl in severely injured rats $\left({ }^{*} p<0.05\right.$; repeated-measures ANOVA with post hoc Tukey's tests). Note that Ve responses to a hypercapnic stimulus were markedly diminished at 2 weeks after $\mathrm{SCI}$ before drug treatment compared with preinjury baselines. 8-OH DPAT treatment resulted in a dose-dependent increase in Ve response; treatment with buspirone also improved Ve response compared with predrug levels. The augmentation of Ve after 8-OH DPAT was blocked by preadministration of the $5-\mathrm{HT}_{1 \mathrm{~A}}$ antagonist $p$-MPPI (PMPPI). C2, Histogram of Ve responses to $7 \% \mathrm{CO}_{2}$ stimulus in rats with severe hemicontusion injury $(50 \mathrm{~mm} ; n=12)$ after $8-0 \mathrm{H}$ DPAT (125 $\mu \mathrm{g} / \mathrm{kg}$ ), 8-OH DPAT ( $250 \mu \mathrm{g} / \mathrm{kg}), p$-MPPI (3 mg/kg), p-MPPI plus 8-OH DPAT (250 $\mu \mathrm{g} / \mathrm{kg})$, or buspirone $(1.5 \mathrm{mg} / \mathrm{kg})$ treatment at 2 weeks after SCl compared with predrug Ve at 2 weeks after SCI and preoperative baselines. Each black horizontal line within each larger colored line represents the distribution of per-breath Ve responses for each rat during hypercapnic challenge.

function experimentally (Lalley et al., 1994; Sahibzada et al., 2000; Teng et al., 2003) and clinically (Mendelsohn et al., 1991). Although the precise mechanisms are not clear, antibody studies have demonstrated the presence of 5- $\mathrm{HT}_{1 \mathrm{~A}}$ on the axon hillocks of ventral horn motoneurons in the cervical spinal cord of primates (Kheck et al., 1995), possibly indicating a direct stimulatory pathway (Takahashi and Berger, 1990; Richmonds and Hudgel, 1996). Because the greatest density of $5-\mathrm{HT}_{1 \mathrm{~A}}$ receptors is found in the superficial layers of the dorsal horns of the spinal cord (Thor et al., 1993; Kheck et al., 1995), we also reasoned that $5-\mathrm{HT}_{1 \mathrm{~A}}$ agonists may, alternatively, act on a pathway involving the afferents from respiratory muscles to supraspinal respiratory centers (Teng et al., 1999).

To further investigate the putative role of $5-\mathrm{HT}_{1 \mathrm{~A}}$ receptor agonists in post-SCI respiration in C5 hemicontusion SCI, a subset of rats with mild $(n=9)$, moderate $(n=9)$, or severe $(n=12)$ injuries and 13 controls underwent testing with 8-OH DPAT at 2 and 4 weeks after SCI. Although long-term effects of the 8-OH DPAT treatments in SCI rats were not systematically examined, no significant differences were noted between the pretreatment respiratory parameters of rats that received occasional $5-\mathrm{HT}_{1 \mathrm{~A}}$ treatments and those that did not receive treatment during the 2 or 4 week postinjury course (data not shown). This indicated that $5-\mathrm{HT}_{1 \mathrm{~A}}$ agonists did not produce early tolerance. The present data revealed that 8-OH DPAT ( $250 \mu \mathrm{g} / \mathrm{kg}$, i.p. $)$ reversed respiratory abnormalities for all rats with hemicontusion injury at both 2 and 4 weeks after injury (Fig. 5A, Table 2). During room air ventilation at 2 weeks after SCI, we observed that 8-OH DPAT 
corrected Vt deficits for all groups with hemicontusion SCI ( $p \leq 0.038$; repeatedmeasures ANOVA with post hoc Tukey's tests) and significantly reduced $f$ in rats in the severely injured group ( $p=0.047$; repeated measures ANOVA with post hoc Tukey's tests), eliminating the shallow, rapid breathing pattern noted before treatment. During 7\% $\mathrm{CO}_{2}$ challenge, $8-\mathrm{OH}$ DPAT treatment significantly improved Ve for all hemicontused groups at 2 weeks $(p \leq 0.001)$ and 4 weeks $(p \leq 0.033$; repeated-measures ANOVA with post hoc Tukey's tests) after injury relative to pretreatment Ve to levels comparable with unlesioned control rats. For instance, severely injured rats at 2 weeks after injury mounted a Ve response to hypercapnic conditions that was $\sim 77 \%$ of uninjured controls, whereas after the severely injured rats received $8-\mathrm{OH}$ DPAT, their response improved by $37.6 \%$ ( $p<0.001$; repeatedmeasures ANOVA with post hoc Tukey's tests) compared with before treatment or $\sim 105 \%$ compared with uninjured controls. At 2 weeks after SCI, moderately injured rats improved their hypercapnic $\mathrm{Ve}$ by $39.2 \%(p<0.001)$ and mildly injured rats by $27.1 \%(p<0.001$; repeatedmeasures ANOVA with post hoc Tukey's tests) compared with predrug baselines to levels comparable with uninjured controls. At 4 weeks after SCI, when predrug baseline hypercapnic Ve for hemicontused animals were improved but still not normal, 8 -OH DPAT improved Ve by $8.4 \%$ in mildly injured rats $(p=0.033), 9.2 \%$ in moderately injured rats $(p=0.025)$, and $28.5 \%$ in severely injured rats $(p=0.001$; repeated- measures ANOVA with post hoc Tukey's tests). Rats without hemicontusion SCI did not display any statistically significant change in ventilatory parameters after 8-OH DPAT treatment at the equivalent time points. As documented previously (Teng et al., 2003), no significant neurobehavioral changes in any group were noted after 8-OH DPAT administration. No discernible adverse effects to any of the drugs under the current dose regimens were noted (Bjorvatn et al., 1997).

To confirm that $5-\mathrm{HT}_{1 \mathrm{~A}}$ receptor agonism plays a central role in respiratory function recovery after $8-\mathrm{OH}$ DPAT administration, a dose washout study, a dose-response study, and additional tests using another $5-\mathrm{HT}_{1 \mathrm{~A}}$ agonist buspirone and $5-\mathrm{HT}_{1 \mathrm{~A}}{ }^{-}$ specific antagonist $p$-MPPI were performed with randomly selected subsets of rats receiving severe hemicontusion injury ( Table 3) (Teng et al., 2003). At $5 \mathrm{~d}$ after SCI, an 8-OH DPAT dose washout study $(250 \mu \mathrm{g} / \mathrm{kg} ; n=4)$ demonstrated a restoration of Ve response to hypercapnia, which peaked during the first hour after injection, lasted up to $4 \mathrm{~h}$, and then subsequently returned to pretreatment levels ( $p \leq 0.024$; repeated-measures ANOVA with post hoc Tukey's test) (Fig. 5B). These results were consistent with our previous data that showed a prolonged (i.e., $4 \mathrm{~h}$ ), but not permanent, amelioration of post-SCI respiratory dysfunction af-
Table 2. Effects of 8-0H DPAT on respiration after $\mathrm{SCI}$

\begin{tabular}{|c|c|c|c|c|c|c|}
\hline Time after SCl & DPAT & $\mathrm{CO}_{2}$ & Control & $12.5 \mathrm{~mm}$ & $25 \mathrm{~mm}$ & $50 \mathrm{~mm}$ \\
\hline \multicolumn{7}{|l|}{2 weeks } \\
\hline \multirow[t]{3}{*}{$f(\mathrm{bpm})$} & - & $0.03 \%$ & $100.4 \pm 3.2$ & $111.0 \pm 4.2$ & $116.4 \pm 3.4$ & $110.8 \pm 4.4$ \\
\hline & + & $0.03 \%$ & $101.1 \pm 1.9$ & $108.3 \pm 2.1$ & $113.4 \pm 5.7$ & $101.6 \pm 2.6$ \\
\hline & & & $p=0.702$ & $p=0.422$ & $p=0.638$ & $p=0.027^{*}$ \\
\hline \multirow[t]{3}{*}{$\mathrm{Vt}(\mathrm{ml})$} & - & $0.03 \%$ & $1.34 \pm 0.04$ & $1.31 \pm 0.03$ & $1.26 \pm 0.03$ & $1.22 \pm 0.04$ \\
\hline & + & $0.03 \%$ & $1.31 \pm 0.03$ & $1.47 \pm 0.04$ & $1.46 \pm 0.07$ & $1.48 \pm 0.06$ \\
\hline & & & $p=0.203$ & $p=0.002^{*}$ & $p=0.016^{*}$ & $p<0.001^{*}$ \\
\hline \multirow[t]{3}{*}{$\mathrm{Ve}(\mathrm{ml} / \mathrm{min})$} & - & $0.03 \%$ & $133.7 \pm 4.3$ & $144.8 \pm 6.2$ & $146.2 \pm 3.3$ & $134.8 \pm 5.5$ \\
\hline & + & $0.03 \%$ & $131.7 \pm 2.8$ & $159.6 \pm 5.1$ & $164.9 \pm 9.5$ & $149.6 \pm 5.8$ \\
\hline & & & $p=0.468$ & $p=0.069$ & $p=0.043^{*}$ & $p=0.099$ \\
\hline \multirow[t]{3}{*}{$f(\mathrm{bpm})$} & - & $7 \%$ & $181.1 \pm 4.2$ & $163.7 \pm 5.5$ & $169.7 \pm 3.8$ & $160.7 \pm 7.3$ \\
\hline & + & $7 \%$ & $182.0 \pm 2.5$ & $188.4 \pm 3.8$ & $194.5 \pm 6.2$ & $183.7 \pm 6.7$ \\
\hline & & & $p=0.155^{*}$ & $p=0.023^{*}$ & $p<0.001^{*}$ & $p<0.001$ \\
\hline \multirow[t]{3}{*}{$\mathrm{Vt}(\mathrm{ml})$} & - & $7 \%$ & $2.91 \pm 0.06$ & $2.73 \pm 0.08$ & $2.42 \pm 0.08$ & $2.49 \pm 0.07$ \\
\hline & + & $7 \%$ & $2.86 \pm 0.05$ & $3.04 \pm 0.10$ & $2.94 \pm 0.16$ & $3.03 \pm 0.06$ \\
\hline & & & $p=0.494^{*}$ & $p<0.001^{*}$ & $p=0.023^{*}$ & $p=0.001$ \\
\hline \multirow[t]{3}{*}{$\mathrm{Ve}(\mathrm{ml} / \mathrm{min})$} & - & $7 \%$ & $527.1 \pm 18.3$ & $449.4 \pm 27.3$ & $412.0 \pm 20.6$ & $403.3 \pm 26.4$ \\
\hline & + & $7 \%$ & $535.8 \pm 10.4$ & $571.5 \pm 13.8$ & $573.6 \pm 38.9$ & $555.1 \pm 17.9$ \\
\hline & & & $p=0.494^{*}$ & $p<0.001^{*}$ & $p=0.005^{*}$ & $p<0.001$ \\
\hline \multicolumn{7}{|l|}{4 weeks } \\
\hline \multirow{3}{*}{$f(\mathrm{bpm})$} & - & $0.03 \%$ & $99.1 \pm 3.0$ & $105.1 \pm 2.1$ & $106.8 \pm 3.8$ & $101.2 \pm 4.0$ \\
\hline & + & $0.03 \%$ & $107.1 \pm 3.9$ & $104.3 \pm 2.6$ & $101.7 \pm 3.0$ & $99.1 \pm 3.3$ \\
\hline & & & $p=0.063$ & $p=0.833$ & $p=0.350$ & $p=0.504$ \\
\hline \multirow[t]{3}{*}{$\mathrm{Vt}(\mathrm{ml})$} & - & $0.03 \%$ & $1.52 \pm 0.05$ & $1.50 \pm 0.05$ & $1.40 \pm 0.06$ & $1.45 \pm 0.05$ \\
\hline & + & $0.03 \%$ & $1.45 \pm 0.06$ & $1.55 \pm 0.05$ & $1.53 \pm 0.04$ & $1.48 \pm 0.06$ \\
\hline & & & $p=0.306$ & $p=0.217$ & $p=0.085$ & $p=0.783$ \\
\hline \multirow[t]{3}{*}{$\mathrm{Ve}(\mathrm{ml} / \mathrm{min})$} & - & $0.03 \%$ & $151.3 \pm 7.9$ & $158.4 \pm 6.7$ & $148.2 \pm 4.9$ & $147.3 \pm 7.9$ \\
\hline & + & $0.03 \%$ & $154.7 \pm 7.4$ & $160.6 \pm 4.7$ & $155.8 \pm 6.0$ & $146.4 \pm 7.0$ \\
\hline & & & $p=0.689$ & $p=0.713$ & $p=0.171$ & $p=0.928$ \\
\hline \multirow[t]{3}{*}{$f(\mathrm{bpm})$} & - & $7 \%$ & $176.8 \pm 7.1$ & $174.9 \pm 6.7$ & $171.8 \pm 7.3$ & $165.0 \pm 5.8$ \\
\hline & + & $7 \%$ & $182.3 \pm 4.7$ & $177.6 \pm 3.5$ & $176.6 \pm 5.9$ & $187.2 \pm 4.6$ \\
\hline & & & $p=0.255$ & $p=0.639$ & $p=0.387^{*}$ & $p<0.001$ \\
\hline \multirow[t]{3}{*}{$\mathrm{Vt}(\mathrm{ml})$} & - & $7 \%$ & $3.09 \pm 0.08$ & $3.01 \pm 0.09$ & $3.12 \pm 0.07$ & $2.64 \pm 0.09$ \\
\hline & + & $7 \%$ & $3.05 \pm 0.07$ & $3.23 \pm 0.09$ & $3.32 \pm 0.06$ & $2.99 \pm 0.15$ \\
\hline & & & $p=0.533$ & $p=0.015^{*}$ & $p<0.001^{*}$ & $p=0.023^{*}$ \\
\hline \multirow[t]{3}{*}{$\mathrm{Ve}(\mathrm{ml} / \mathrm{min})$} & - & $7 \%$ & $544.6 \pm 23.6$ & $530.6 \pm 32.7$ & $536.2 \pm 25.2$ & $437.9 \pm 26.5$ \\
\hline & + & $7 \%$ & $556.6 \pm 21.4$ & $575.2 \pm 24.0$ & $585.6 \pm 21.2$ & $562.7 \pm 36.4$ \\
\hline & & & $p=0.449$ & $p=0.048^{*}$ & $p=0.038^{*}$ & $p<0.001^{*}$ \\
\hline
\end{tabular}

Effects of systemic 8-OH DPAT ( $250 \mu \mathrm{g} / \mathrm{kg}$ ) administration on respiratory parameters $(f, \mathrm{Vt}$, and Ve) for rats without $\mathrm{SCl}(n=13)$ or mild $(n=9)$, moderate $(n=9)$, or severe $(n=12)$ hemicontusion injury at 2 or 4 weeks after SCI. Data revealed that 8-OH DPAT restored minute ventilation during hypercapnic challenge $\left(7 \% \mathrm{CO}_{2}\right)$ in rats with all grades of hemicontusion injury to levels similar to uninjured controls at both 2 and 4 weeks after SCl $(p \leq 0.033$; repeatedmeasures ANOVA). Respiratory parameters for uninjured rats were not significantly affected by 8-OH DPAT administration at either 2 or 4 weeks after the baseline period ( ${ }^{*} p<0.05$; repeated-measures ANOVA with post hoc Tukey's tests).

Table 3. Effects of various agents with $5-\mathrm{HT}_{1 \mathrm{~A}}$ receptor activity on respiration after $\mathrm{SCl}$

\begin{tabular}{llll}
\hline & $f(\mathrm{bpm})$ & $\mathrm{Vt}(\mathrm{ml})$ & $\mathrm{Ve}(\mathrm{ml} / \mathrm{min})$ \\
\hline Pre-SCl & $182.9 \pm 8.5$ & $2.94 \pm 0.09$ & $537.7 \pm 29.6$ \\
Predrug (2 weeks after SCl) & $160.7 \pm 7.3^{\dagger}$ & $2.50 \pm 0.08^{\dagger}$ & $404.3 \pm 26.8^{\dagger}$ \\
8-OH DPAT $(125 \mu \mathrm{g} / \mathrm{kg})$ & $173.9 \pm 6.3$ & $2.77 \pm 0.06^{* \dagger}$ & $479.7 \pm 15.6^{* \dagger}$ \\
8-OH DPAT $(250 \mu \mathrm{g} / \mathrm{kg})$ & $183.7 \pm 5.0^{*}$ & $3.03 \pm 0.06^{*}$ & $555.1 \pm 17.9^{*}$ \\
$\begin{array}{l}p \text {-MPPI }(3 \mathrm{mg} / \mathrm{kg}) \\
\quad \text { plus 8-0H DPAT (250 } \mu \mathrm{g} / \mathrm{kg})\end{array}$ & $158.7 \pm 7.3^{\dagger}$ & $2.43 \pm 0.06^{\dagger}$ & $380.7 \pm 24.9^{\dagger}$ \\
Buspirone (1.5 mg/kg) & $180.7 \pm 5.6^{*}$ & $2.91 \pm 0.08^{*}$ & $524.8 \pm 21.7^{*}$ \\
Repeated-measures ANOVA & $p<0.001$ & $p<0.001$ & $p<0.001$ \\
\hline
\end{tabular}

Respiratory responses to hypercapnic stimulus $\left(7 \% \mathrm{CO}_{2}\right)$ for rats with severe hemicontusion injury $(50 \mathrm{~mm} ; n=12)$ at preinjury baseline or 2 weeks after SCl under predrug, 8-OH DPAT (125 $\mu \mathrm{g} / \mathrm{kg}), 8-0 \mathrm{H}$ DPAT $(250 \mu \mathrm{g} / \mathrm{kg}), p-\mathrm{MPPI}$ ( $3 \mathrm{mg} / \mathrm{kg}), p$-MPPI $(3 \mathrm{mg} / \mathrm{kg})$ plus 8-OH DPAT $(250 \mu \mathrm{g} / \mathrm{kg})$, or buspirone $(1.5 \mathrm{mg} / \mathrm{kg})$. All numbers are presented as mean \pm SEM. The asterisk indicates a significant difference from predrug on post hoc Tukey's test $(p<0.05)$, and the dagger symbol indicates a significant difference from 8-OH DPAT ( $250 \mu \mathrm{g} / \mathrm{kg}$ ) on post hoc Tukey's test $(p<$ 0.05 ) after significant differences were found on repeated-measures ANOVA.

ter a single intraperitoneal administration of 8-OH DPAT (Teng et al., 2003). The four rats that received 8-OH DPAT at $5 \mathrm{~d}$ after SCI did not display differences in respiratory parameters on subsequent WBP testing for the remainder of their studies compared 
with the other severely injured rats, suggesting no long-term effect on respiratory function after the single 8-OH DPAT injection at $5 \mathrm{~d}$ after SCI (data not shown). Finally, 8-OH DPAT administration did not enhance respiratory response to $7 \% \mathrm{CO}_{2}$ in control rats.

In the dose-response study performed at 2 weeks after SCI $(n=12)$, a dose-dependent restoration of hypercapnic Ve response was observed. The $250 \mu \mathrm{g} / \mathrm{kg}$ dose of $8-\mathrm{OH}$ DPAT produced the greatest improvement in Ve versus predrug baseline (37.2\% increase; $p<0.001$ ), followed by the $125 \mu \mathrm{g} / \mathrm{kg}$ dose (18.6\% increase; $p<0.038$; repeated-measures ANOVA with post hoc Tukey's tests) (Fig. 5C, Table 3). In other separate studies during the second week after injury, preadministration of p-MPPI (3 mg/kg, i.p.), given $20 \mathrm{~min}$ before 8-OH DPAT, blocked the beneficial effects of $8-\mathrm{OH}$ DPAT $(250 \mu \mathrm{g} / \mathrm{kg})$. Whereas 8-OH DPAT ( $250 \mu \mathrm{g} / \mathrm{kg})$ significantly improved hypercapnic Ve compared with the predrug baseline $(p<0.001$; see above) when $p$-MPPI was given before 8-OH DPAT, hypercapnic Ve did not significantly differ from predrug baseline $(p>0.05$; repeated-measures ANOVA with post hoc Tukey's test). Buspirone $(1.5 \mathrm{mg} / \mathrm{kg}$, i.p.; $n=12)$, like 8 -OH DPAT, also improved Ve under hypercapnic conditions significantly greater than the predrug baseline $(29.8 \%$ increase; $p=0.003)$ to levels indiscernible from the pre-SCI response $(p>0.05$; repeated-measures ANOVA with post hoc Tukey's tests). Together, the results strongly supported the proposition that the respiratory benefits seen in our model were mediated through $5-\mathrm{HT}_{1 \mathrm{~A}}$ receptors.

\section{Discussion}

Previous reports examining respiratory dysfunction after SCI examined pathophysiology in either thoracic models or anesthetized rats (El-Bohy et al., 1998; Teng et al., 1999, 2003; Golder et al., 2001). These studies were pivotal but showed only transient dysfunction or were necessarily terminal. This is the first report of the impact of a contusive cervical SCI on respiratory function in conscious rats with chronic clinical manifestations. Our model offers feasible laboratory procedures while emulating the epidemiology of disease and the clinical features of post-SCI respiratory dysfunction (Gruner, 1992; Manning et al., 1992). Using this model, we demonstrated that systemic $5-\mathrm{HT}_{1 \mathrm{~A}}$ agonists counteracted post-SCI respiratory abnormalities without discernable adverse effects.

\section{Greater chronicity of respiratory dysfunction after C5 hemicontusion than thoracic SCI likely to be associated with phrenic nucleus involvement in the $\mathrm{C} 5$ model}

We speculate that involvement of the phrenic nucleus ipsilateral to the hemicontusion was accountable for the greater chronicity of respiratory deficits in our cervical model than after T8 SCI. The phrenic nucleus of the rat is a longitudinal column of cells located between the ventromedial and ventrolateral cell groups of the ventral horn, extending from C3 to C5 or sometimes C6 (Kuzuhara and Chou, 1980; DeVries and Goshgarian, 1989). Here, we demonstrated an obliteration of this midventral region at the C5 epicenters of all hemicontused groups, with the loss extending partially through the $\mathrm{C} 4$ and $\mathrm{C} 6$ levels. Thus, the hemidiaphragm ipsilateral to the hemicontusion was, at least in part, denervated.

Although the precise contribution of the rat diaphragm to various respiratory parameters has yet to be described, indubitably, the diaphragm plays a more significant role than the lower thoracic intercostals in rodent respiration (e.g., the human diaphragm normally contributes $\sim 65 \%$ of vital capacity) (Ledsom and Sharp, 1981). Thus, after midcervical injury, potential natu- ral compensatory mechanisms involving the intercostals are not likely to fully compensate for diminished diaphragmatic function, whereas in the thoracic injury model, increased diaphragmatic function might overcome respiratory deficits attributable to intercostal muscle dysfunction. A more fruitful compensatory measure after C5 hemicontusion is likely to be increased diaphragmatic drive via supraspinal pathways. Our observation of an increased $f$ during the early postinjury period was compatible with this postulation. However, this rapid breathing pattern can be detrimental to gas exchange and culminate in hypoxemia or frank respiratory failure (Ledsom and Sharp, 1981; Rochester, 1993).

\section{Eventual recovery of respiratory function}

The eventual recovery of respiratory dysfunction observed in this study is consistent with clinical observations (Bluechardt et al., 1992). Although mechanisms underlying this recovery are essentially unknown, it is well documented that a hemiparetic diaphragm ipsilateral to a $\mathrm{C} 2$ hemisected cord can regain function shortly after the contralateral phrenic nerve is transected, or spontaneously $\sim 4$ weeks after injury (O'Hara and Goshgarian, 1991; Nantwi et al., 1999; Golder et al., 2003). The so-called "crossed phrenic phenomenon" works by reactivating silent synapses of the bulbospinal pathways that cross the spinal midline caudal to the C2 lesion (O'Hara and Goshgarian, 1991). Because our hemicontusion SCI obliterated the majority of the ipsilateral phrenic area, the recovery was unlikely to be mediated by crossed phrenic pathways.

Alternatively, respiratory recovery may have been partially caused by reinnervation of the hemicontusion SCI-denervated hemidiaphragm through axonal sprouting from spared ipsilateral phrenic neurons, contralateral phrenic neurons, and/or phrenic terminals. This reinnervation may potentially have been enhanced by our $5-\mathrm{HT}_{1 \mathrm{~A}}$ agonist administrations, because 5- $\mathrm{HT}_{1 \mathrm{~A}}$ activation triggers functional respiratory neural plasticity (Giroux et al., 1999; Mantilla and Sieck, 2003). However, the delay in our initial administration of $5-\mathrm{HT}_{1 \mathrm{~A}}$ agonists fell far beyond the therapeutic windows for tissue preservation after SCI (Teng et al., 1997, 1998, 2004), precluding any hope for 5- $\mathrm{HT}_{1 \mathrm{~A}}$ agonist-triggered neuroprotection in our study. Nevertheless, it remains to be examined whether earlier and/or more frequent administration of serotoninergic agonists can further improve or elicit a more prompt neuroplasticity for respiratory recovery.

\section{Amelioration of respiratory dysfunction by $5-\mathrm{HT}_{1 \mathrm{~A}}$ agonists} In our study, we observed a temporary restoration (lasting up to $4 \mathrm{~h}$ ) of respiratory function in C5-injured rats after systemic $5-\mathrm{HT}_{1 \mathrm{~A}}$ agonists at 2 and 4 weeks after injury. The mechanism by which $5-\mathrm{HT}_{1 \mathrm{~A}}$ agonists improve respiration after SCI is not clear (Teng et al., 2003). One possibility is through a dorsal horn afferent-supraspinal respiratory center pathway (Thor et al., 1993; Jankowska et al., 1997; Teng et al., 2003). Briefly, respiratory muscle afferents can influence brainstem respiratory centers and ultimately affect motor output to the skeletal muscles responsible for breathing. It has been suggested that the transfer of information from these respiratory muscle afferents to supraspinal centers may be gated by descending serotonergic, presumably 5-HT $\mathrm{HA}_{1 \mathrm{~A}}$, pathways (Jankowska et al., 1997; Teng et al., 2003). Buspirone and 8-OH DPAT may act on the dorsal horns of rats with SCI to modulate these pathways and restore normal respiratory function (Teng et al., 2003). We observed a correlation between hypercapnic Ve responses and motoneuronal count in the rostral, but not caudal, margins of the lesion epicenter. It is 
our speculation that any positive modulation of the dorsal spinal-supraspinal pathway should trigger a corresponding increase in Ve response to hypercapnia, because the rostral marginal motoneurons would primarily have synaptic continuity with supraspinal centers.

Another possible mechanism explaining the effect of 5-HT $1 \mathrm{~A}$ agonists is via diaphragmatic-thoracic reflex loops. Such reflexes increase accessory respiratory neuronal output (i.e., thoracic motor neurons that control intercostal and abdominal muscles) after their activation by phrenic sensory input from diaphragmatic proprioceptors and mechanoreceptors (Goshgarian and Roubal, 1986). After hemicontusion SCI, certain ipsilateral proprioceptive fibers could still be stimulated by contralateral hemidiaphragmatic contraction (Monteau and Hilaire, 1991). Serotonin $1 \mathrm{~A}$ agonists may have stimulated this reflex loop, a testable hypothesis for future experiments.

It might be postulated that our observed respiratory recovery could have been augmented through $5-\mathrm{HT}_{2}$ receptor activation and expression, as reported after $\mathrm{C} 2$ hemisection (Zhou et al., 2001; Fuller et al., 2005) and cervical dorsal rhizotomy (CDR) (Kinkead et al., 1998). Post-CDR rats displayed increased serotonin-immunoreactive terminals on phrenic motor neurons, and the consequent long-lasting enhancement of phrenic motor output triggered by hypoxia was blocked by pretreatment with a 5- $\mathrm{HT}_{2}$-specific antagonist. However, 8-OH DPAT and buspirone used in our work are 5- $\mathrm{HT}_{1 \mathrm{~A}}$ specific. 8-OH DPAT, for instance, has an $\sim 1000$-fold selectivity for the $5-\mathrm{HT}_{1 \mathrm{~A}}$ over the other 5 -HT receptors (Middlemiss and Fozard, 1983), and its respiratory effect observed in this study was completely blocked by $p$-MPPI, a highly specific $5-\mathrm{HT}_{1 \mathrm{~A}}$ antagonist $\left(\mathrm{Ki}_{5-\mathrm{HT} 1 \mathrm{~A}}=1.0 \mathrm{vs} \mathrm{Ki}_{5-\mathrm{HT} 2}=\right.$ $270 \mathrm{~nm}$ ) (Kung et al., 1994). Nevertheless, we are currently testing whether coadministration of $5 \mathrm{HT}_{1 \mathrm{~A}}$ and $5 \mathrm{HT}_{2 \mathrm{~A}}$ agonists would synergistically or additively improve post-SCI respiratory recovery.

The evidence supporting a direct supraspinal action for $5-\mathrm{HT}_{1 \mathrm{~A}}$ agonists in post-SCI respiratory dysfunction is less clear. Although 5- $\mathrm{HT}_{1 \mathrm{~A}}$ presynaptic and postsynaptic receptors are well known to be distributed in supraspinal areas such as the limbic regions, dorsal raphe nuclei, and various cortical regions and have complex interactions (Blier and Ward, 2003), the respiratory effects after 5- $\mathrm{HT}_{1 \mathrm{~A}}$ agonist exposure are unclear. Respiratory frequencies, for instance, have increased in some reports (Mandal et al., 1990; Rose et al., 1995) while remaining level in others (King and Holtman, 1990). Moreover, complexities in the study designs, including dose and route of drug administration (e.g., intravenous, intraventricular, or direct parenchymal injection), anesthesia use, or use of decerebrate models make interpretations of these studies difficult. Anesthesia is a particularly troublesome factor in the study of serotonin and respiration, because anesthetics may easily reduce the excitatory serotonergic input to motoneurons (Rose et al., 1995). In vitro brainstem-spinal cord preparations of neonatal rats have shown that addition of $8-\mathrm{OH}$ DPAT to the superfusate increased respiratory frequency to $28 \pm$ $7 \%$ greater than controls (Monteau et al., 1994). Other studies have shown that 8-OH DPAT has little effect on output from key brainstem respiratory centers (Johnson et al., 1996, 2001). However, emphasis must be made that none of these models incorporated a clinically relevant SCI in their designs.

Additional studies will be needed to precisely define the mechanisms through which $5-\mathrm{HT}_{1 \mathrm{~A}}$ agonists ameliorate respiratory dysfunction in this experiment and others. In light of the pressing need for clinical therapeutics applicable to post-SCI respiratory dysfunction and the availability of buspirone, a well tolerated clinical $5-\mathrm{HT}_{1 \mathrm{~A}}$ agonist used as an anxiolytic, we believe that $5-\mathrm{HT}_{1 \mathrm{~A}}$ agonists may offer a novel strategy for treating post-SCI respiratory dysfunction. These data, together with the fact that $5-\mathrm{HT}_{1 \mathrm{~A}}$ agonists corrected respiratory deficits in rats with a significant loss of one of their primary phrenic nuclear regions, suggest that strategies aimed at augmenting function and/or expression levels of 5-HT receptors should be further explored to develop treatments for SCI via functional repair of the gray matter (Teng et al., 1999, 2003; Reier et al., 2002) in addition to the well studied tactics for white matter protection (Teng and Wrathall, 1997; Stys, 1998; Waxman, 2002). Importantly, our model will allow additional investigations of other promising pharmaceutical avenues for this highly morbid and occasionally fatal complication of SCI (Nantwi et al., 2003).

\section{References}

Basso DM, Beattie MS, Bresnahan JC (1995) A sensitive and reliable locomotor rating scale for open field testing in rats. J Neurotrauma 12:1-21.

Bjorvatn B, Fagerland S, Eid T, Ursin R (1997) Sleep/waking effects of a selective $5-\mathrm{HT}_{1 \mathrm{~A}}$ receptor agonist given systemically as well as perfused in the dorsal raphe nucleus in rats. Brain Res 770:81-88.

Blier P, Ward NM (2003) Is there a role for 5-HT1A agonists in the treatment of depression? Biol Psychiatry 53:193-203.

Blight AR (1983) Cellular morphology of chronic spinal cord injury in the cat: analysis of myelinated axons by line-sampling. Neuroscience 10:521-543.

Bluechardt MH, Wiens M, Thomas SG, Plyley MJ (1992) Repeated measurements of pulmonary function following spinal cord injury. Paraplegia 30:768-774.

DeVries KL, Goshgarian H (1989) Spinal cord localization and characterization of the neurons which give rise to the accessory phrenic nerve in the adult rat. Exp Neurol 104:88-90.

El-Bohy AA, Schrimsher GW, Reier PJ, Goshgarian HG (1998) Quantitative assessment of respiratory function following contusion injury of the cervical spinal cord. Exp Neurol 150:143-152.

Epstein RA, Epstein MAF, Haddad GG, Mellins RB (1980) Practical implementation of the barometric method for measurement of tidal volume. J Appl Physiol 49:1107-1115.

Feldman JL, Mitchell GS, Nattie EE (2003) Breathing: rhythmicity, plasticity, chemosensitivity. Annu Rev Neurosci 26:239-266.

Fuller DD, Baker-Herman TL, Golder FJ, Doperalski NJ, Watters JJ, Mitchell GS (2005) Cervical spinal cord injury upregulates ventral spinal 5- $\mathrm{HT}_{2 \mathrm{~A}}$ receptors. J Neurotrauma 22:203-213.

Gale K, Kerasidis H, Wrathall JR (1985) Spinal cord contusion in the rat: behavioral analysis of functional neurological impairment. Exp Neurol $88: 123-134$.

Giroux N, Rossignol S, Reader TA (1999) Autoradiographic study of alpha 1 and alpha 2 noradrenergic and serotonin $1 \mathrm{~A}$ receptors in the spinal cord of normal and chronically transected cats. J Comp Neurol 406:402-414.

Go BK, DeVivo MJ, Ricards JS (1995) The epidemiology of spinal cord injury. In: Spinal cord injury: clinical outcomes of the model systems (Stover SL, DeLisa JA, Whiteneck GG, eds), pp 21-55. Gaithersburg, MD: Aspen.

Golder FJ, Reier PJ, Bolser DC (2001) Altered respiratory motor drive after spinal cord injury: supraspinal and bilateral effects of a unilateral lesion. J Neurosci 21:8680-8689.

Golder FJ, Fuller DD, Davenport PW, Johnson RD, Reier PJ, Bolser DC (2003) Respiratory motor recovery after unilateral spinal cord injury: eliminating crossed phrenic activity decreases tidal volume and increases contralateral respiratory motor output. J Neurosci 23:2494-2501.

Goshgarian HG, Roubal PJ (1986) Origin and distribution of phrenic primary afferent nerve fibers in the spinal cord of the adult rat. Exp Neurol 92:624-638.

Gray PA, Janczewski WA, Mellen N, McCrimmon DR, Feldman JL (2001) Normal breathing requires preBotzinger complex neurokinin- 1 receptorexpressing neurons. Nat Neurosci 4:927-930.

Grossman SD, Rosenberg LJ, Wrathall JR (2001) Temporal-spatial pattern of acute neuronal and glial loss after spinal cord contusion. Exp Neurol 168:273-282. 
Gruner JA (1992) A monitored contusion model of spinal cord injury in the rat. J Neurotrauma 9:123-128.

Jankowska E, Hammar I, Djouhri L, Heden C, Szabo-Lackberg Z, Yin XK (1997) Modulation of responses to four types of feline ascending tract neurons by serotonin and noradrenaline. Eur J Neurosci 9:1375-1387.

Johnson SM, Smith JC, Feldman JL (1996) Modulation of respiratory rhythm in vitro: role of Gi/O protein-mediated mechanisms. J Appl Physiol 80:2120-2133.

Johnson SM, Wilkerson JER, Henderson DR, Wenninger MR, Mitchell GS (2001) Serotonin elicits long-lasting enhancement of rhythmic respiratory activity in turtle brain stems in vitro. J Appl Physiol 91:2703-2712.

Kheck NM, Gannon PJ, Azmitia EC (1995) 5- $\mathrm{HT}_{1 \mathrm{~A}}$ receptor localization on the axon hillock of cervical spinal motoneurons in primates. J Comp Neurol 355:211-220.

King KA, Holtman Jr JR (1990) Characterization of the effects of activation of ventral medullary serotonin receptor subtypes on cardiovascular activity and respiratory motor outflow to the diaphragm and larynx. J Pharmacol Exp Ther 252:665-674.

Kinkead R, Zhan WZ, Prakash YS, Bach KB, Sieck GC, Mitchell GS (1998) Cervical dorsal rhizotomy enhances serotonergic innervation of phrenic motoneurons and serotonin-dependent long-term facilitation of respiratory motor output in rats. J Neurosci 18:8436-8443.

Kleinbaum DG, Kupper LL, Muller KE, Nizam A (1998) Analysis of repeated measures data. In: Applied regression analysis and other multivariable methods, Chap 21, Ed 3, pp 589-638. Pacific Grove, CA: Duxbury.

Kung MP, Zhang ZP, Frederick D, Kung HF (1994) In vivo binding of $\left[{ }^{123} \mathrm{I}\right]$ 4-(2'-methoxyphenyl)-1-[2'-(N-2'-pyridinyl)-p-iodobenzamido-] ethylpiperazine, $\mathrm{p}$-MPPI, to $5-\mathrm{HT}_{1 \mathrm{~A}}$ receptors in rat brain. Synapse 18:359-366.

Kuzuhara S, Chou SM (1980) Localization of the phrenic nucleus in the rat: a HRP study. Neurosci Lett 16:119-124.

Lai YL, Tsuya Y, Hildebrandt J (1978) Ventilatory responses to acute $\mathrm{CO}_{2}$ exposure in the rat. J Appl Physiol 45:611-618.

Lalley PM, Bischoff AM, Richter DW (1994) Serotonin 1A receptor activation suppresses respiratory apneusis in the cat. Neurosci Lett 172:59-62.

Ledsom JR, Sharp JM (1981) Pulmonary function in acute cervical cord injury. Am Rev Respir Dis 124:41-44.

Linn WS, Spungen AM, Gong Jr H, Adkins RH, Bauman WA, Waters RL (2001) Forced vital capacity in two large outpatient populations with chronic spinal cord injury. Spinal Cord 39:263-268.

Mandal AK, Zhong PY, Kellar KJ, Gillis RA (1990) Ventrolateral medulla: an important site of action for the hypotensive effect of drugs that activate the serotonin-1A receptors. J Cardiovasc Pharmacol 15 [Suppl 71:S49-S60.

Manning HL, Brown R, Scharf SM, Leith DE, Weiss JW, Weinberger SE, Schwartzstein RM (1992) Ventilatory and $\mathrm{P}_{0.1}$ response to hypercapnia in quadriplegia. Respir Physiol 89:97-112.

Mantilla CB, Sieck GC (2003) Plasticity in respiratory motor control: invited review: mechanisms underlying motor unit plasticity in the respiratory system. J Appl Physiol 94:1230-1241.

Mendelsohn WB, Maczaj M, Holt J (1991) Buspirone administration to sleep apnea patients. J Clin Psychopharmacol 11:71-72.

Middlemiss DN, Fozard JR (1983) 8-Hydroxy-2-(di-N-propylamino)tetralin discriminates between subtypes of the $5-\mathrm{HT}_{1}$ recognition site. Eur J Pharmacol 90:151-153.

Mitchell GS, Johnson SM (2003) Neuroplasticity in respiratory motor control. J Appl Physiol 94:358 -374.

Monteau R, Hilaire G (1991) Spinal respiratory motoneurons. Prog Neurobiol 37:83-144.

Monteau R, Pasquale ED, Hilaire G (1994) Further evidence that various 5-HT receptor subtypes modulate central respiratory activity: in vitro studies with SR 46349B. Eur J Pharmacol 259:71-74.

Nantwi KD, El-Bohy AA, Schrimsher GW, Reier PJ, Goshgarian HG (1999) Spontaneous functional recovery in a paralyzed hemidiaphragm following upper cervical spinal cord injury in adult rats. Neurorehab Neural Repair 13:225-234.

Nantwi KD, Basura GJ, Goshgarian HG (2003) Effects of long-term theophylline exposure on recovery of respiratory function and expression of adenosine A1 mRNA in cervical spinal cord hemisected adult rats. Exp Neurol 182:232-239.
Newsom Davis J, Plum F (1972) Separation of descending spinal pathways to respiratory motoneurons. Exp Neurol 34:78-94.

Noble LJ, Wrathall JR (1989) Correlative analysis of lesion development and functional status after graded spinal cord contusive injuries in the rat. Exp Neurol 103:34-40.

O'Hara TE, Goshgarian GH (1991) Quantitative assessment of phrenic nerve functional recovery mediated by the crossed phrenic reflex at various time intervals after spinal cord injury. Exp Neurol 111:244-250.

Raineteau O, Fouad K, Noth P, Thallmair M, Schwab ME (2001) Functional switch between motor tracts in the presence of the mAb IN-1 in the adult rat. Proc Natl Acad Sci USA 98:6929-6934.

Reier PJ, Golder FJ, Bolser DC, Hubscher C, Johnson R, Schrimsher GW, Velardo MJ (2002) Gray matter repair in the cervical spinal cord. Prog Brain Res 37:49-70.

Richmonds CR, Hudgel DW (1996) Hypoglossal and phrenic motoneuron responses to serotonergic active agents in rats. Respir Physiol 106:153-160.

Rochester DF (1993) Respiratory muscles and ventilatory failure: 1993 perspective. Am J Med Sci 305:394-402.

Rose D, Khater-Boidin J, Toussaint P, Duron B (1995) Central effects of 5-HT on respiratory and hypoglossal activities in the adult cat. Respir Physiol 101:59-69.

Sahibzada N, Ferreira M, Wasserman AM, Taveira-DaSilva AM, Gillis RA (2000) Reversal of morphine-induced apnea in the anesthetized rat by drugs that activate 5-hydroxytryptamine (1A) receptors. J Pharmacol Exp Ther 292:704-713.

Stephenson R, Gucciardi EJ (2002) Theoretical and practical considerations in the application of whole body plethysmography to sleep research. Eur J Appl Physiol 87:207-219.

Stys PK (1998) Anoxic and ischemic injury of myelinated axons in CNS white matter: from mechanistic concepts to therapeutics. J Cereb Blood Flow Metab 18:2-25.

Takahashi T, Berger AJ (1990) Direct excitation of rat spinal motoneurons by serotonin. J Physiol (Lond) 423:63-76.

Teng YD, Wrathall JR (1996) Evaluation of cardiorespiratory parameters in rats after spinal cord trauma and treatment with NBQX, an antagonist of excitatory amino acid receptors. Neurosci Lett 209:5-8.

Teng YD, Wrathall JR (1997) Local blockade of sodium channels by tetrodotoxin ameliorates tissue loss and long-term functional deficits resulting from experimental spinal cord injury. J Neurosci 17:4359-4366.

Teng YD, Mocchetti I, Wrathall JR (1998) Basic and acidic fibroblast growth factors protect spinal motor neurons in vivo after experimental spinal cord injury. Eur J Neurosci 10:798-802.

Teng YD, Mocchetti I, Taveira-DaSilva AM, Gillis RA, Wrathall JR (1999) Basic fibroblast growth factor increases long-term survival of spinal motor neurons and improves respiratory function after experimental spinal cord injury. J Neurosci 19:7037-7047.

Teng YD, Bingaman M, Taveira-DaSilva AM, Pace PP, Gillis RA, Wrathall JR (2003) Serotonin 1A receptor agonists reverse respiratory abnormalities in spinal cord-injured rats. J Neurosci 23:4182-4189.

Teng YD, Choi H, Onario RC, Zhu S, Desilets FC, Lan S, Woodard EJ, Snyder EY, Eichler ME, Friedlander RM (2004) Minocycline inhibits contusion-triggered mitochondrial cytochrome $c$ release and mitigates functional deficits after spinal cord injury. Proc Natl Acad Sci USA 101:3071-3079.

Thor KB, Nickolaus S, Helke CJ (1993) Autoradiographic localization of 5-hydroxytryptamine 1A, 5-hydroxytryptamine $1 \mathrm{~B}$ and 5-hydroxytryptamine $1 \mathrm{C}$ binding sites in the rat spinal cord. Neuroscience 55:235-252.

Waxman SG (2002) Ion channels and neuronal dysfunction in multiple sclerosis. Arch Neurol 59:1377-1380.

Winslow C, Rozovsky J (2003) Effect of spinal cord injury on the respiratory system. Am J Phys Med Rehab 82:803-814.

Zhou SY, Goshgarian H (2000) 5-Hydroxytryptophan-induced respiratory recovery after cervical spinal cord hemisection in rats. J Appl Physiol $89: 1528-1536$.

Zhou SY, Basura GJ, Goshgarian HG (2001) Serotonin(2) receptors mediate respiratory recovery after cervical spinal cord hemisection in adult rats. J Appl Physiol 91:2665-2673. 